\title{
Influence of Quality of Land Levelling on Soil Moisture Variability in Safflower Fields
}

\author{
P. S. Kanannavar, R. Vasantgouda*, Kumar Lamani, \\ B. C. Punitha and U. K. Shanawad
}

IWMRC, Belavatagi, University of Agricultural Sciences, Dharwad, India

*Corresponding author

\section{Keywords}

Quality of land levelling, Levelling index, Soil moisture, Spatial variability, Safflower

\section{Article Info}

Accepted:

10 April 2020

Available Online:

10 May 2020

\begin{abstract}
A B S T R A C T
The quality of land development/ levelling is having enormous impact on soil moisture storage and distribution in the field both spatially and temporally, crop growth, yields and irrigation water saving. So, unevenness of agricultural fields leads to the in-efficient use of irrigation water, which in turn reduces the yield and farm income. The quality and accuracy of land levelling determined by term "Levelling index" (LI) are dynamic factors. Consequently, it is imperative to study the impact of levelling indices on soil moisture distribution in fields. A field experiment was conducted in the research farms of Irrigation Water Management Research Center (IWMRC), Belvatagi, University of Agricultural Sciences (UAS) Dharwad during Rabi 2018 to assess influence of quality of land levelling on soil moisture variability in safflower fields. The results indicated spatial variability with respect to levelling indices and soil moisture in the same fields with average LI ranging from $1.37 \mathrm{~cm}$ to $2.28 \mathrm{~cm}$ and average soil moisture ranging from $32.26 \%$ to $35.94 \%$. Also, it was found that the soil moisture variability was evident (standard deviation of soil moisture varying from 3.31 to $9.59 \%$ ) with respect to the quality of land levelling irrespective of the safflower varieties. Hence, better quality of land levelling reduces soil moisture distribution variability to increase irrigation efficiency.
\end{abstract}

\section{Introduction}

In irrigated agriculture, the quality of land development or land levelling is having huge impact on soil moisture distribution, storage and variability in the field both spatially and temporally, crop growth, yields and irrigation efficiency. Agriculture land levelling plays a key role because undulating topography of the fields has a major impact on the germination, water movement, water saving and crop yields. A significant (20-25\%) amount of irrigation water is lost during its application at the farm due to poor farm design and unevenness of the field (Cook and Peikert, 1960). Scientific land levelling saves irrigation water by facilitating field operations and increasing crop yields (Rickman, 2002). 
For an efficient irrigation system the level difference between high and low spots of a field should not exceed $20 \mathrm{~mm}$ whereas under actual field conditions, a difference of 10 to $30 \mathrm{~cm}$ is very common. Hence dynamic levelling parameters such as standard deviation of elevations and levelling index determine the accuracy and quality of land levelling which affects soil moisture distribution and its variability. For enhancing irrigation efficiency for agricultural sustainability the soil moisture variability needs to be avoided. So the present study during Rabi 2018 was conducted to assess influence of quality of land levelling on soil moisture variability in safflower fields of Irrigation Water Management Research Center (IWMRC), Belvatagi, University of Agricultural Sciences (UAS) Dharwad, Karnataka.

Leveling index $=\frac{\sum \text { Numerical difference } \text { between the designed and existing grid levels }}{\text { Number of grid points }}$

\section{Materials and Methods}

In the present study, a safflower crop was taken up as a multi location trial (MLT) in vertisols at IWMRC Belavatagi, UAS Dharawd as shown in Fig.1. MLT was with 14 safflower varieties $\mathrm{V}_{1}$ to $\mathrm{V}_{14}$ with 3 replications as shown in Fig.2. A filed topographic survey was carried out to find quality of land levelling by calculating levelling index (LI) of the field. Soil moisture variations as affected by LI was observed. Total 4 irrigations were given with depths of $78 \mathrm{~mm}, 57 \mathrm{~mm}, 95 \mathrm{~mm}$ and $57 \mathrm{~mm}$, respectively. After an irrigation event of 78 $\mathrm{mm}$ depth, soil moisture $(0-10 \mathrm{~cm}$ depth) was measured with the help of theta probe. (Fig.3.). The levelling index was calculated using the formula given by Agarwal and Goel.(1981).
An irrigation event was considered for soil moisture $(0-10 \mathrm{~cm})$ variability studies. The influence of levelling index on soil moisture variability in the field after an irrigation event was observed. The standard deviation of soil moisture was calculated to know the spatial variability.

\section{Results and Discussion}

From Table.1 It was observed that the spatial variability with respect to levelling index and soil moisture in the same fields with average LI ranging from $1.37 \mathrm{~cm}$ to $2.28 \mathrm{~cm}$ and average soil moisture ranging from $32.26 \%$ to $35.94 \%$. Also, it was found that the soil moisture variability was evident (standard deviation of soil moisture varying from 3.31 to $9.59 \%$ ) with respect to the quality of land levelling. Levelling index Versus Soil moisture curves for all 14 varieties show the effect of LI on soil moisture distribution as shown in Figures. 4 to 17 . From all the curves it was observed that the general trend of decreasing soil moisture with increase in Levelling index. The increase in levelling index indicates the decrease the quality of levelling conditions with undulating micro topography of the fields. Thus the effect of microtopography of the field affects soil moisture distribution and ultimately irrigation performance. The same inferences were corroborated by Playan et al., (1996) and Bai et al., (2011)

Conclusions of the study are as follows:

Quality of land levelling is very importance in irrigated agriculture to ensure uniform soil moisture conditions to the crops

The variability in levelling index indicating undulating micro topography leads to soil moisture variability 
It is found that soil moisture variability was lower with the lower Levelling index irrespective of varieties of safflower
Advanced levelling techniques like Laser land levelling can be adopted to increase irrigation efficiency and crop yields

Table.1 Land levelling index $(\mathrm{cm})$ and soil moisture (\%) for different varieties of safflower

\begin{tabular}{|c|c|c|c|c|c|c|c|}
\hline \multirow{2}{*}{ Sl. No. } & \multirow{2}{*}{ Variety } & \multicolumn{3}{|c|}{ Levelling index, cm } & \multicolumn{3}{c|}{ Soil moisture $(\mathbf{V} / \mathbf{V}), \%$} \\
\hline & & $\mathrm{R}_{1}$ & $\mathrm{R}_{2}$ & $\mathrm{R}_{3}$ & $\mathrm{R}_{1}$ & $\mathrm{R}_{2}$ & $\mathrm{R}_{3}$ \\
\hline $\mathbf{1}$ & $\mathrm{V}_{1}$ & 1.11 & 1.78 & 2.74 & 34.69 & 32.69 & 33.54 \\
\hline $\mathbf{2}$ & $\mathrm{V}_{2}$ & 1.48 & 1.95 & 1.26 & 33.04 & 31.52 & 32.86 \\
\hline $\mathbf{3}$ & $\mathrm{V}_{3}$ & 1.60 & 1.93 & 1.68 & 33.49 & 31.73 & 35.18 \\
\hline $\mathbf{4}$ & $\mathrm{V}_{4}$ & 1.31 & 1.80 & 1.38 & 38.32 & 31.56 & 31.60 \\
\hline $\mathbf{5}$ & $\mathrm{V}_{5}$ & 2.10 & 1.78 & 1.73 & 33.08 & 31.93 & 35.13 \\
\hline $\mathbf{6}$ & $\mathrm{V}_{6}$ & 1.33 & 1.48 & 1.98 & 36.20 & 34.54 & 32.88 \\
\hline $\mathbf{7}$ & $\mathrm{V}_{7}$ & 1.95 & 1.11 & 2.32 & 37.91 & 35.53 & 34.38 \\
\hline $\mathbf{8}$ & $\mathrm{V}_{8}$ & 1.85 & 1.63 & 1.46 & 30.99 & 29.59 & 36.20 \\
\hline $\mathbf{9}$ & $\mathrm{V}_{9}$ & 1.28 & 1.41 & 2.52 & 37.50 & 33.81 & 29.71 \\
\hline $\mathbf{1 0}$ & $\mathrm{V}_{10}$ & 0.79 & 1.83 & 2.37 & 33.48 & 33.48 & 31.27 \\
\hline $\mathbf{1 1}$ & $\mathrm{V}_{11}$ & 1.23 & 3.88 & 1.73 & 33.08 & 32.33 & 32.88 \\
\hline $\mathbf{1 2}$ & $\mathrm{V}_{12}$ & 2.47 & 1.48 & 1.11 & 31.10 & 30.79 & 35.14 \\
\hline $\mathbf{1 3}$ & $\mathrm{V}_{13}$ & 1.04 & 1.41 & 1.68 & 34.93 & 35.16 & 32.53 \\
\hline $\mathbf{1 4}$ & $\mathrm{V}_{14}$ & 1.73 & 1.68 & 1.46 & 31.30 & 32.11 & 36.11 \\
\hline
\end{tabular}

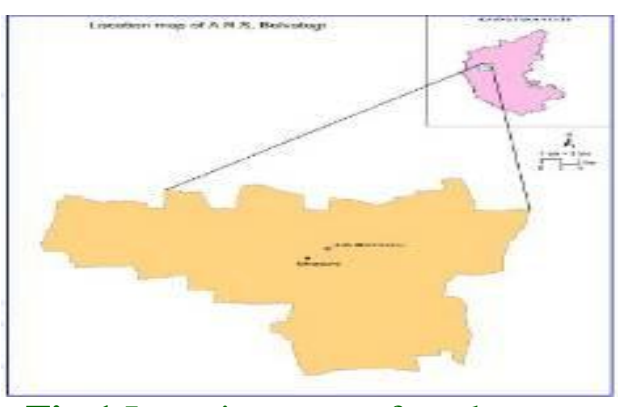

Fig.1 Location map of study area

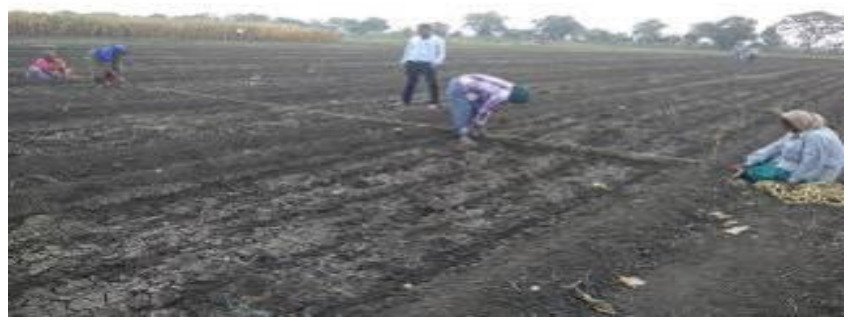

Fig.2 Laying out of field experiment

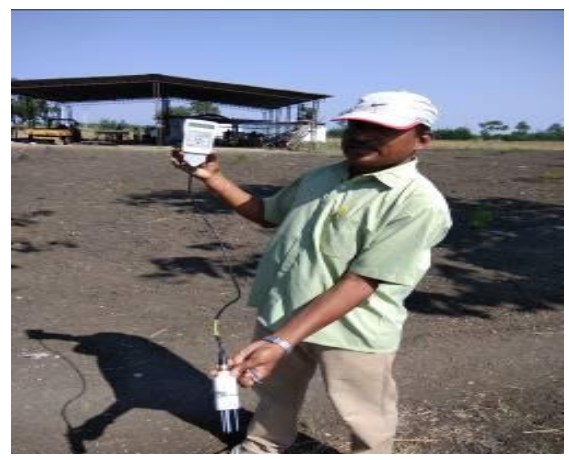

Fig.3 Theta probe for soil moisture measurement 
Figs.4 to 17 Levelling index Versus Soil moisture curves for Varieties of safflower $V_{1}$ to $V_{14}$
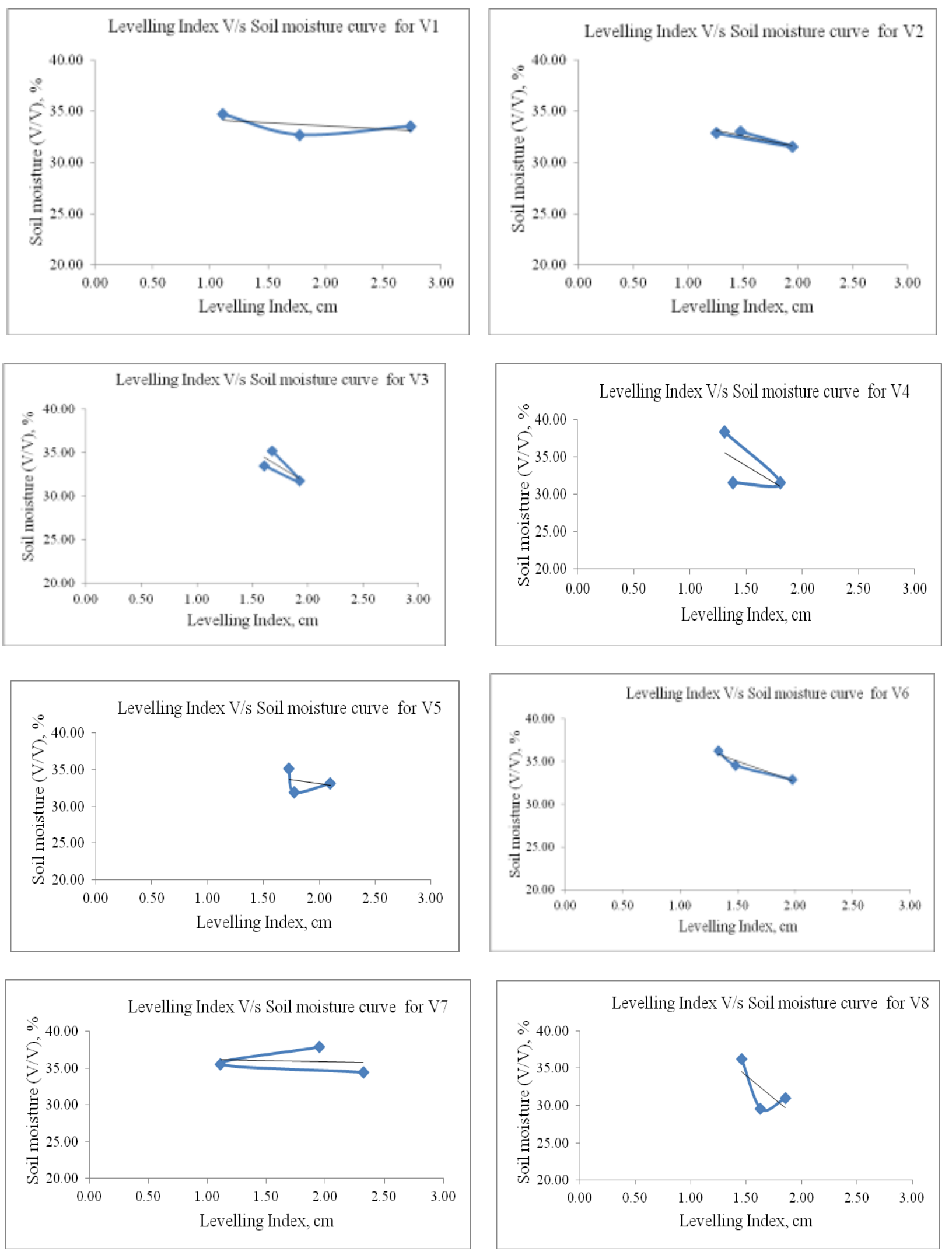

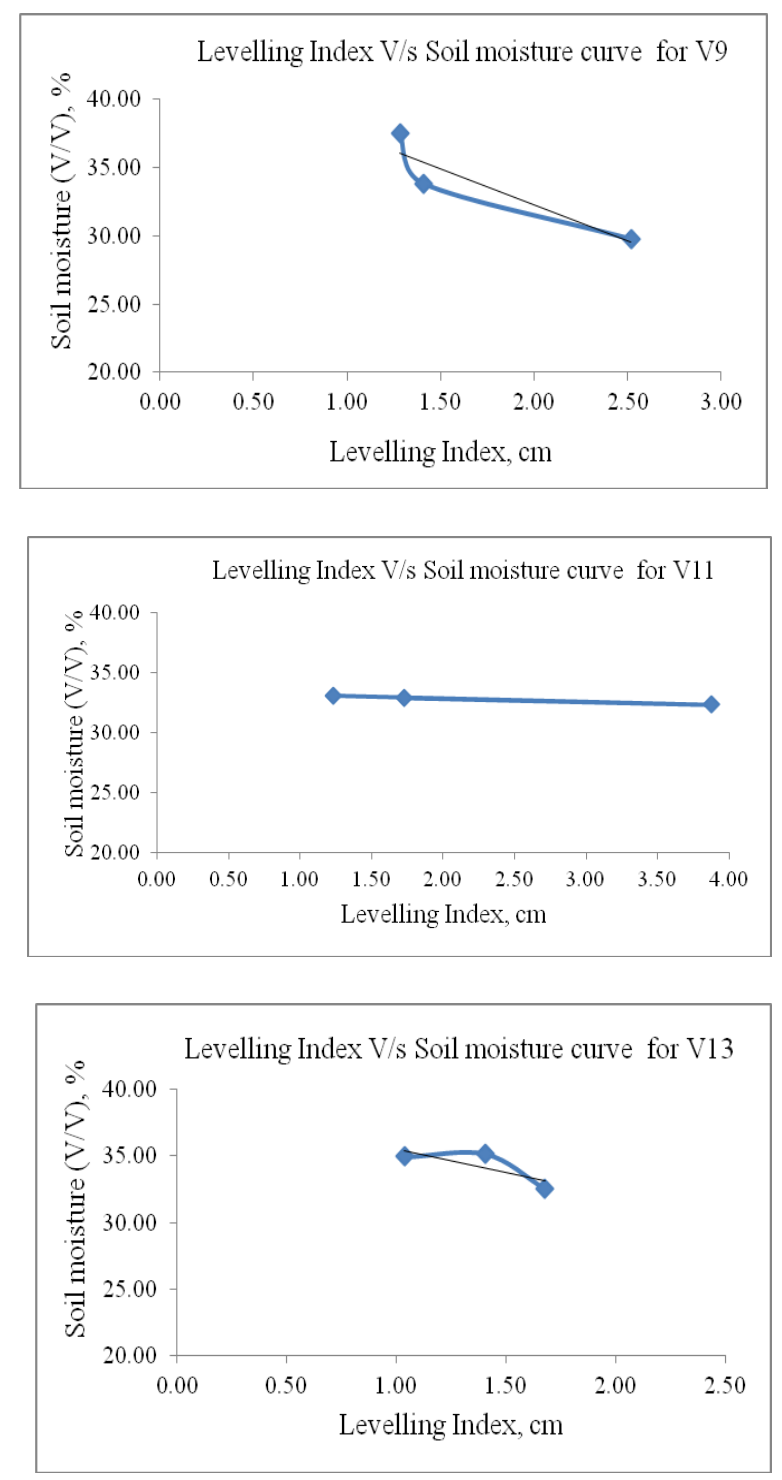

\section{References}

Agarwal, M.C and Goel, A. C., 1981. Effect of field levelling quality on irrigation efficiency and crop yield. Agricultural Water Management ,4: 457-464

Bai, M. J., Xu, D., Li, Y. N., Pereira, L. S., 2011, Impacts of spatial variability of basins microtopography on irrigation performance, Irrig. Sci., 29: 359-368.

Cook, R. L. and F.W. Peikert, 1960. A comparison of tillage implement. The Journal of American Society of
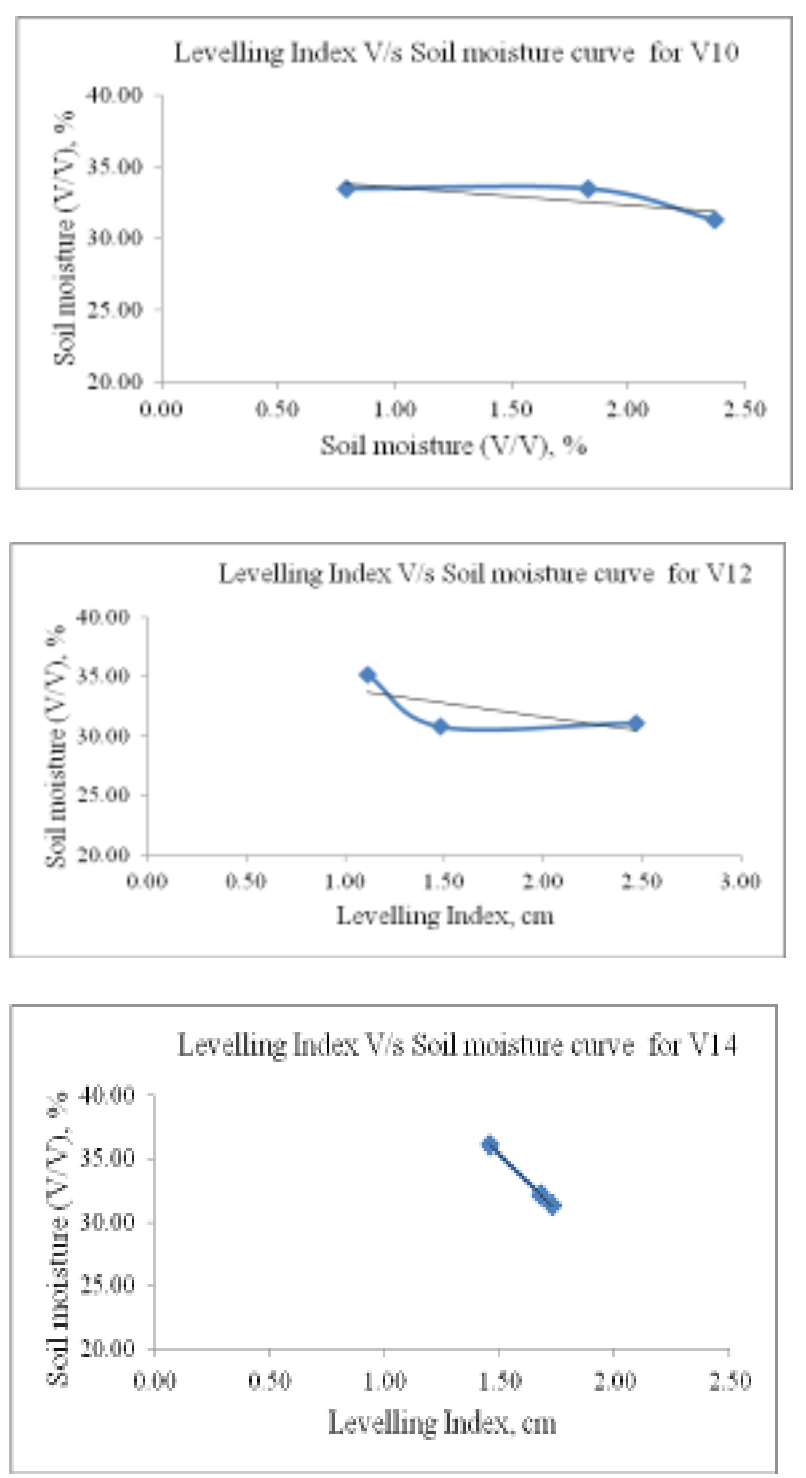

Agricultural Engineers. Vol. 31: 211214.

Playan, E., Faci, J. M. and Serreta, A., 1996, Characterizing micro topographical effects on level-basin irrigation performance. Agric. Water Man., 29:129-145.

Rickman, J. F., 2002. "Manual for laser land leveling”. Rice-Wheat Consortium Technical Bulletin Series 5. New Delhi110 012, India: Rice-Wheat Consortium for the Indo-Gangetic plains, p24. 


\section{How to cite this article:}

Kanannavar, P. S., R. Vasantgouda, Kumar Lamani, B. C. Punitha and Shanawad, U. K. 2020. Influence of Quality of Land Levelling on Soil Moisture Variability in Safflower Fields. Int.J.Curr.Microbiol.App.Sci. 9(05): 1415-1420. doi: https://doi.org/10.20546/ijcmas.2020.905.161 